\title{
Pseudostalked barnacles Xenobalanus globicipitis attached to killer whales Orcinus orca in South African waters
}

Thomas Otto Whitehead ${ }^{1 *}$, Dominic Paul Rollinson ${ }^{1}$, Ryan Rudolf Reisinger ${ }^{2}$

${ }^{1}$ Percy FitzPatrick Institute, DST/NRF Centre of Excellence, University of Cape Town, Private Bag X3, Rondebosch 7701, South Africa

${ }^{2}$ Mammal Research Institute, Department of Zoology and Entomology, University of Pretoria, Private Bag X20, Hatfield 0028, South Africa

*corresponding author: whitehead.otto@gmail.com, Tel.+27216503291

\begin{abstract}
Several records describe pseudostalked barnacles Xenobalanus globicipitis attached to killer whales Orcinus orca, yet little is known of this association in Southern African waters. Here we describe Xenobalanus prevalence on killer whales in South African waters and assemble previous records. Killer whales were photographed opportunistically between July and September 2013. Sex and age class were determined, and if Xenobalanus were present, attachment site and colony size noted. A prevalence of $50 \%$ was recorded, with barnacles most commonly observed on the dorsal fin and tail flukes. The high prevalence of Xenobalanus on killer whales in South African waters and lack thereof on killer whales at Marion Island implies that these are separate populations, and thus we suggest Xenobalanus prevalence is an additional means to distinguish between these populations.
\end{abstract}

KEYWORDS: Xenobalanus globicipitis, Orcinus orca, killer whale, barnacle, epibiont, South Africa

\section{INTRODUCTION}

The pseudostalked barnacle Xenobalanus globicipitis (hereafter referred to as Xenobalanus) is a specialised epibiont, living only on cetaceans (Kane et al. 2008). This association is commensal as Xenobalanus does not 
feed on its cetacean host, but simply benefits from being transported. Xenobalanus has a cosmopolitan distribution, ranging from the Arctic to Antarctica (Kane et al. 2008). The small diameter of its six-plated balanomorph shell enables it to pierce and securely embed itself into the integument of its host (Seilacher 2005). It is most commonly observed attached to the trailing edges of the host's dorsal fin, pectoral flippers or tail flukes (Kane et al. 2008), but in rare cases also attaches to the rostrum and area between the teeth (Samaras 1989). Xenobalanus has been documented on a wide range of cetaceans off the coast of South Africa (Rajaguru and Shantha 1992); however, there are few records of Xenobalanus associated with killer whales Orcinus orca (Best 2007). This association has been recorded in the Mediterranean (Gruvel 1920; Richard 1936), North Atlantic Ocean (Foote et al. 2011), eastern Pacific Ocean (Samaras 1989; Fertl 1996; Guerrero-Ruiz and Urban 2000; Kane et al. 2008) and western Pacific Ocean (Sakai et al. 2009). Here we describe the prevalence of Xenobalanus globicipitis attached to killer whales observed off the coast of South Africa from July to September 2013 and assemble previous records of this association in South African waters.

\section{MATERIALS AND METHODS}

Killer whales were photographed opportunistically whilst conducting observations aboard a tuna longline fishing vessel off the South African coast from July to September 2013 (Fig. 1). Sex and age class (adult, subadult, calf) of killer whales were judged from size and shape of the dorsal fin, and overall body size and form. If barnacles were present, attachment site and minimum number of discernable barnacles (colony size) were noted. No specimens were collected; however, photographs were sufficient in identifying barnacles as Xenobalanus globicipitis. This monotypic species is distinguished from the similar-looking stalked barnacle Conchoderma virgatum by its narrower peduncle and darker colouration (Kane et al. 2008). Additionally, images collated from a photographic identification study of killer whales at Marion Island (Fig. 1) ongoing since 2006 (Reisinger et al. 2011; Reisinger and de Bruyn 2014) were also examined for the presence of Xenobalanus.

\section{RESULTS}

Overall, 82 photographs of 16 individual killer whales (five adult males, seven adult females, one sub-adult male, one sub-adult female, and two unidentifiable) were taken. Eight individuals had infestations of Xenobalanus (50\% prevalence); 3 adult females (37.5\%), 2 adult males (25\%), 1 sub-adult male (12.5\%), 1 sub- 


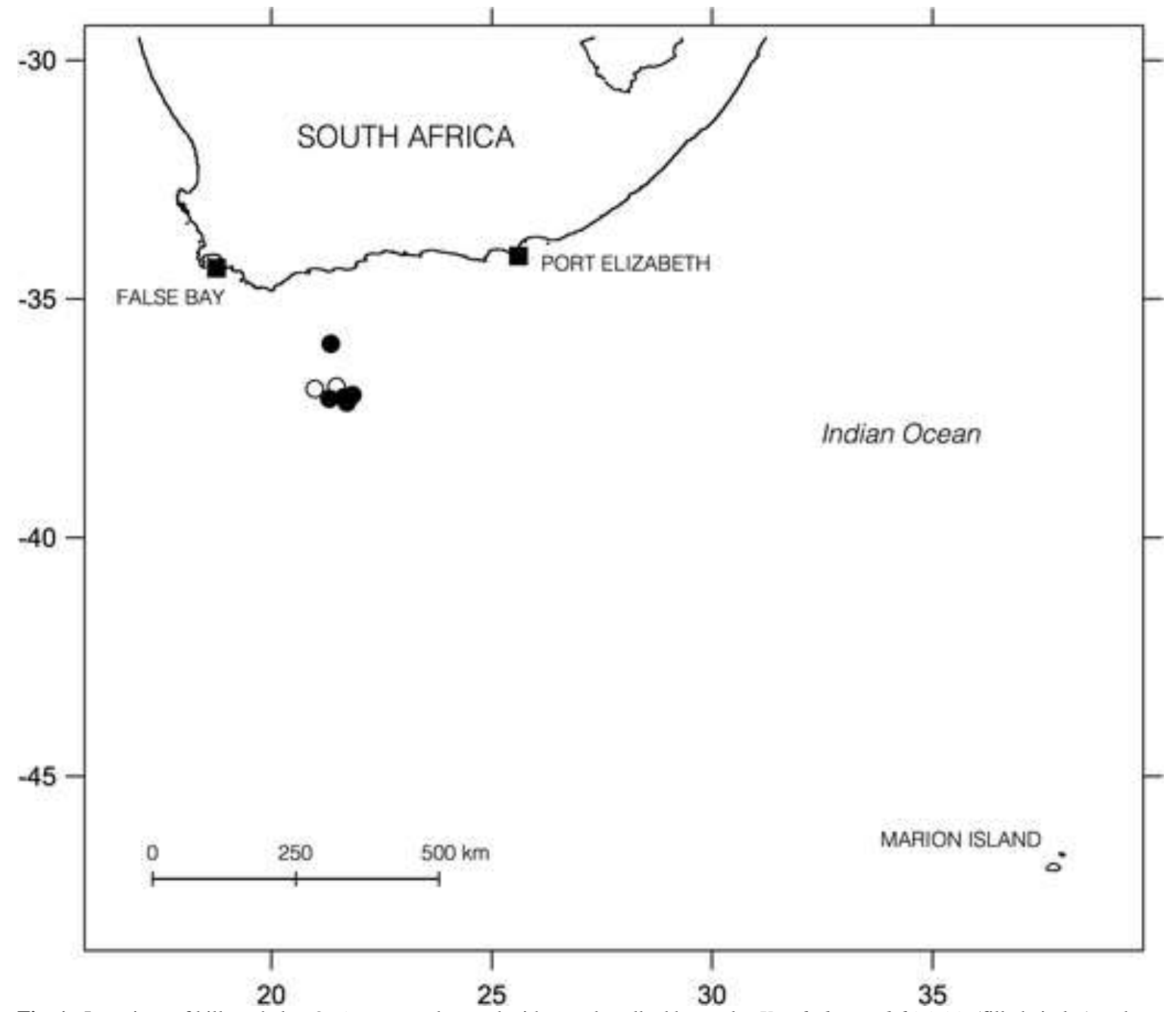

Fig. 1 : Locations of killer whales Orcinus orca observed with pseudostalked barnacles Xenobalanus globicipitis (filled circles) and without (empty circles) during July-September 2013. Squares denote locations of additional observations 


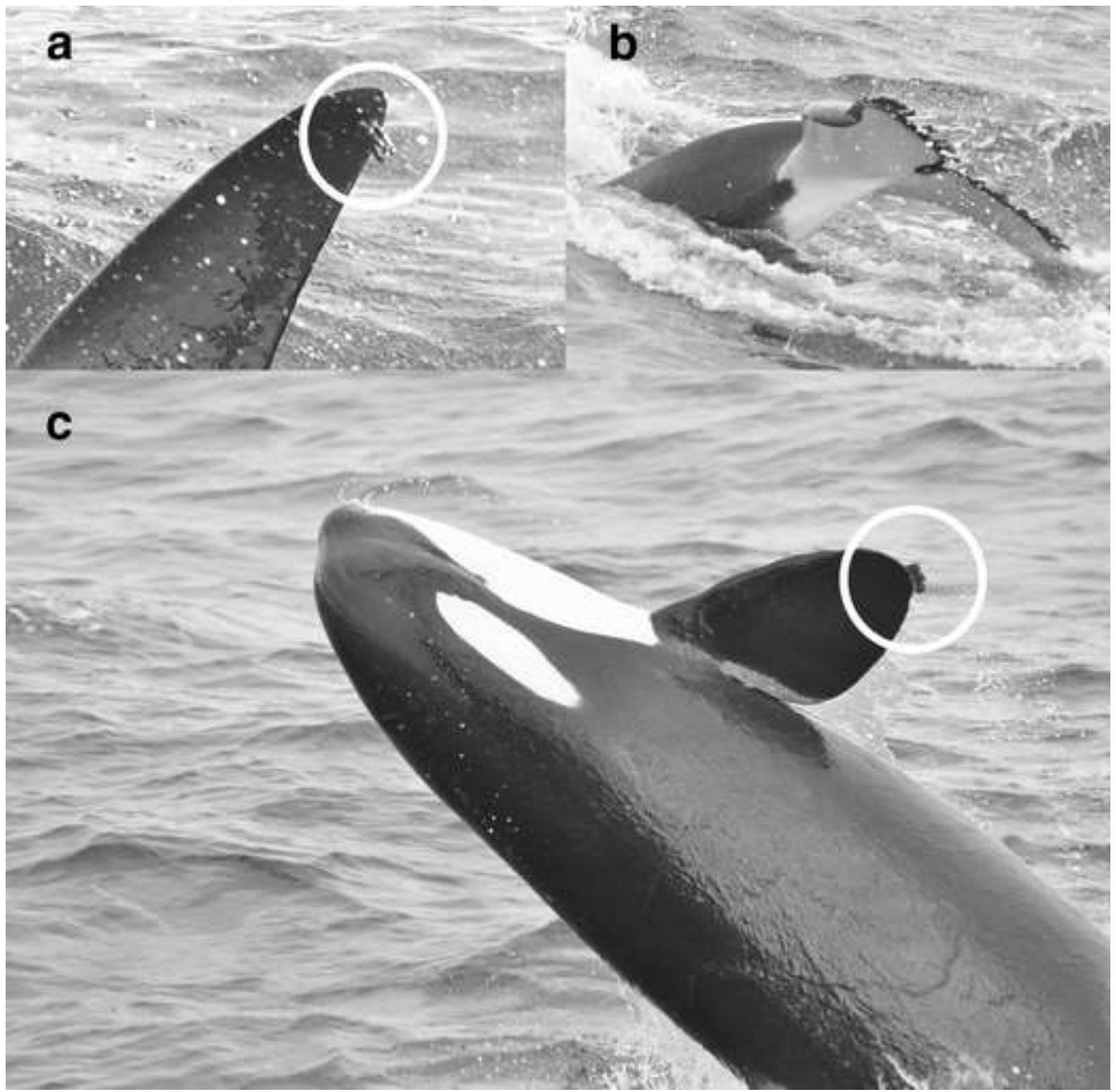

Fig. 2 : Photographs of Xenobalanus globicipitis attached to the dorsal fin (a), tail flukes (b), and pectoral flipper (c) of killer whales Orcinus orca off the coast of South Africa (photo credits: DR Rollinson) 
adult female (12.5\%) and 1 unidentifiable (12.5\%). Most killer whales were observed with infestations at a single site (75\%), with only two individuals having infestations at two sites (25\%). Infestations were most common on the tail flukes (40\%) and dorsal fin (40\%), with fewest on pectoral flippers (20\%) (Fig. 2). Overall, mean colony size was $7.1 \pm 5.8$ individuals (ranging from one to 20 individuals). Mean colony sizes on tail flukes, pectoral flippers and the dorsal fin were $11.8 \pm 5.9(\mathrm{n}=4), 8 \pm 0(\mathrm{n}=2)$ and $2.0 \pm 0.8(\mathrm{n}=4)$ individuals, respectively. At Marion Island, 39,000 images of 57 identifiable killer whales were taken during 1,611 sightings of killer whales (Reisinger et al. 2011; Reisinger and de Bruyn 2014) and no infestations of Xenobalanus were observed.

\section{DISCUSSION}

There are few records of Xenobalanus attached to killer whales in South African waters, yet this association seems to be common. The small number of records may reflect the scarcity of killer whale sightings in South African waters (Best 2010), observer bias, or that Xenobalanus simply goes unreported. We report a prevalence of $50 \%$ among killer whales sighted off South Africa. Previous groups of killer whales sighted in False Bay and off Port Elizabeth (Fig. 1) contained at least 3 out of $12(25 \%)$ and 1 out of $3(33.3 \%)$ infested animals, respectively (David Hurwitz ${ }^{1}$ pers. comm. and Lloyd Edwards ${ }^{2}$ pers. comm.; Suppl. Figs. S1 and S2). The latter sighting was an adult male with Xenobalanus attached to the dorsal fin and tail flukes (Suppl. Fig. S2). Best (2007) noted that of eight killer whales examined in the South African subregion, Xenobalanus was attached to two (25\%); one individual had 30 attached to its tail flukes, while the other had seven on its tail flukes and 14 on its pectoral flippers. Records of Xenobalanus attached to killer whales in the eastern North Pacific indicate that this association is common, with $68 \%$ of killer whales sighted from 1977 to 2003 possessing Xenobalanus (Kane et al. 2008).

While Xenobalanus is associated with many cetacean species and appears widespread, little is known about the mechanisms driving its occurrence (Toth et al. 2012). Early life history strategies of Xenobalanus have not been described and thus knowledge on the biology and ecology of this monotypic species has been inferred exclusively from observations of Xenobalanus on cetacean hosts. The presence of Xenobalanus in Arctic to

\footnotetext{
${ }^{1}$ Simon’s Town Boat Company, Town Pier, Simon’s Town 7995, South Africa

${ }^{2}$ Raggy Charters, PO Box 15317, Emerald Hill 6011, South Africa
} 
Antarctic waters (Bushuev 1990; Kane et al. 2008; Olafsdottir and Shinn 2013) indicates that, as adults, the species has a wide thermal tolerance. However, given that water temperature is suggested as an important determinant of Xenobalanus prevalence (Van Waerebeek et al. 1993; Orams and Schuetze 1998) and that most sightings of Xenobalanus on cetaceans have been recorded in temperate and tropical seas (Rajaguru and Shantha 1992; Kane et al. 2008), this species may have optimal thermal preferences as adults and/or as larvae. Orams and Schuetze (1998) noted a seasonal decline in Xenobalanus infestations on bottlenose dolphins off Australia as water temperatures increased from 18 to $24^{\circ} \mathrm{C}$, suggesting an upper thermal tolerance threshold. Similarly, Van Waerebeek et al. (1993) noted that peak infestations of dusky dolphins off Peru occurred during periods of strongest upwelling, indicating the role of upwelling (and perhaps the associated cooler waters and increased nutrients) in controlling the swarming of nauplius larvae. Additionally, Kane et al. (2008) observed that Xenobalanus presence in the eastern Pacific Ocean was related to primary production, suggesting that low plankton abundance in oligotrophic areas may indirectly limit the presence of the filter-feeding Xenobalanus by influencing food availability. The waters immediately south of South Africa are highly productive, of moderate temperatures $\left(\sim 17.5-23.5^{\circ} \mathrm{C}\right)$ (Rouault and Lutjeharms 2003), and function as vital swarming grounds for many planktonic larvae (Hutchings et al. 2002). It is possible that these waters, which support a large diversity of cetaceans (Best 2007), provide ideal habitat for Xenobalanus larvae to aggregate and settle.

Interestingly, there were no recorded occurrences of Xenobalanus among killer whales sighted at Marion Island - approximately $1,800 \mathrm{~km}$ south east of our sightings - despite this being well within the potential movement range of killer whales (Best et al. 2010; Matthews et al. 2011); a killer whale satellite tagged at Marion Island travelled to $35^{\circ} \mathrm{S}$ (RR Reisinger and PJN de Bruyn ${ }^{3}$ unpubl. data). Mean annual sea surface temperature at Marion Island is $5^{\circ} \mathrm{C}$ (Mélice et al. 2003), much colder than where we made our observations (Fig. 1). Commensal organisms are often used as biological tags to make inferences about host populations. Bushuev (1990) showed Xenobalanus prevalence was useful in distinguishing minke whale stocks during summer, reasoning that whales overwintered in distinct areas differing in their prevalence of Xenobalanus infestation. Similarly, Xenobalanus prevalence was among the factors Toth et al. (2012) used to delineate sympatric bottlenose dolphin stocks in the western Atlantic Ocean. The high prevalence of Xenobalanus infestations on killer whales observed in South African waters and the lack of infestations on killer whales sighted at Marion

\footnotetext{
${ }^{3}$ Mammal Research Institute, Department of Zoology and Entomology, University of Pretoria, Private Bag X20, Hatfield 0028, South Africa
} 
Island supports evidence that these are two separate populations, and thus the occurrence of Xenobalanus may provide researchers an additional means to distinguish between them.

\section{ACKNOWLEDGEMENTS}

The authors thank Lloyd Edwards of Raggy Charters and David Hurwitz of Simon's Town Boat Company for providing additional killer whale observations and two reviewers for their comments. Funding for killer whale work at Marion Island was provided by the National Research Foundation (NRF) Thuthuka programme, the South African Department of Science and Technology through the NRF, the Mohamed bin Zayed Species Conservation Fund (project number: 10251290) and the International Whaling Commission's Southern Ocean Research Partnership. The Department of Environmental Affairs supplied logistic support within the South African National Antarctic Programme.

\section{CONFLICT OF INTEREST}

The authors declare they have no conflicting interests.

\section{REFERENCES}

Best PB (2007) Whales and dolphins of the Southern African Subregion. Cambridge University Press, Cape Town

Best PB, Meÿer MA, Lockyer C (2010) Killer whales in South African waters - a review of their biology. Afr J Mar Sci 32:171-186

Bushuev S (1990) A study of the population structure of the southern minke whale (Balaenoptera acutorostrata Lacépède) based on morphological and ecological variability. Rep Int Whal Comm 40:317-324

Fertl D, Acevedo-Gutierrez A, Darby FL (1996) A report of killer whales (Orcinus orca) feeding on a carcharhinid shark in Costa Rica. Mar Mamm Sci 12:606-611

Foote AD, Vilstrup JT, De Stephanis R, Verborgh P, Abel Nielsen SC, Deaville R, Kleivane L, Martín V, Miller 
PJ, Oien N, Pérez-Gil M, Rasmussen M, Reid RJ, Robertson KM, Rogan E, Similä T, Tejedor ML, Vester H, Víkingsson GA, Willerslev E, Gilbert MT, Piertney SB (2011) Genetic differentiation among North Atlantic killer whale populations. Mol Ecol 20:629-641

Gruvel A (1920) Cirrhipedes provenant des campagnes scientifiques de S.A.S. le Prince de Monaco (18851913). Result Campagnes Sci Accomp sur son yacht par Albert I, Prince Souverain de Monaco 53:1-88

Guerrero-Ruiz M, Urban JR (2000) First report of remoras on two killer whales (Orcinus orca) in the Gulf of California, Mexico. Aquat Mamm 26:148-150

Hutchings L, Beckley LE, Griffiths MH, Roberts MJ, Sundby S, van der Lingen C (2002) Spawning on the edge: spawning grounds and nursery areas around the southern African coastline. Mar Freshwater Res 53:307318

Kane EA, Olson PA, Gerrodette TG, Fiedler PC (2008) Prevalence of the commensal barnacles Xenobalanus globicipitis on cetacean species in the eastern tropical Pacific Ocean, and a review of global occurrence. Fish Bull 106: 395-404

Matthews CJD, Luque SP, Petersen SD, Andrews RD, Ferguson SH (2011) Satellite tracking of a killer whale (Orcinus orca) in the eastern Canadian Arctic documents ice avoidance and rapid, long-distance movement into the North Atlantic. Polar Biol 34:1091-1096

Mélice J-L, Lutjeharms JRE, Rouault M, Ansorge IJ (2003) Sea-surface temperatures at the sub-Antarctic islands Marion and Gough during the past 50 years. S Afr J Sci 99:363-366

Olafsdottir D, Shinn AP (2013) Epibiotic macrofauna on common minke whales, Balaenoptera acutorostrata Lacépède, 1804, in Icelandic waters. Parasit Vectors 6:105-114

Orams MB, Schuetze C (1998) Seasonal and age/size-related occurrence of a barnacle (Xenobalanus globicipitis) on bottlenose dolphins (Tursiops truncatus). Mar Mamm Sci 14:186-189

Rajaguru A, Shantha G (1992) Association between the sessile barnacle Xenobalanus globicipitis (Coronulidae) and the bottlenose dolphin Tursiops truncatus (Delphinidae) from the Bay of Bengal, India, with a summary of previous records from cetaceans. Fish B-NOAA 90:197-202 
Reisinger RR, de Bruyn PJN (2014) Marion Island killer whales: 2006-2013. Mammal Research Institute,

University of Pretoria, Pretoria. DOI: 10.6084/m9.figshare.971317

Reisinger RR, de Bruyn PJN, Bester MN (2011) Abundance estimates of killer whales at subantarctic Marion Island. Aquatic Biol 12:177-185

Richard J (1936) Documents sur les cetaces et pinnipedes provenant des Campagnes du Prince Albert $1^{\mathrm{er}}$ de Monaco. Result Campagnes Sci 94:1-71

Rouault M, Lutjeharms J (2003) Estimation of sea-surface temperature around southern Africa from satellitederived microwave observations: research letter. S Afr J Sci 99:489-494

Sakai Y, Hayashi R, Murata K, Yamada TK, Asakawa M. (2009) Records of barnacle, Xenobalanus globicipitis Steenstrup, 1851 and whale lice, Cyamus sp. from a wild killer whale captured in the western North Pacific, off Kii Peninsula, Japan. Japan J Zoo Wildlife Med 14:81-84

Samaras W (1989) New host record for the barnacle Cryptolepas rhachianecti Dall, 1872 (Balanomorpha: Coronulidae). Mar Mamm Sci 5:84-87

Seilacher A (2005) Whale barnacles: exaptational access to a forbidden paradise. Paleobiology 31:27-35

Toth JL, Hohn A, Able KW, Gorgone AM (2012) Defining bottlenose dolphin (Tursiops truncatus) stocks based on environmental, physical, and behavioral characteristics. Mar Mamm Sci 28:461-478

Van Waerebeek K, Reyes JC, Alfaro J (1993) Helminth parasites and phoronts of dusky dolphins Lagenorhynchus obscurus (Gray, 1828) from Peru. Aquat Mamm 19:159-169 
SUPPLEMENTARY MATERIAL

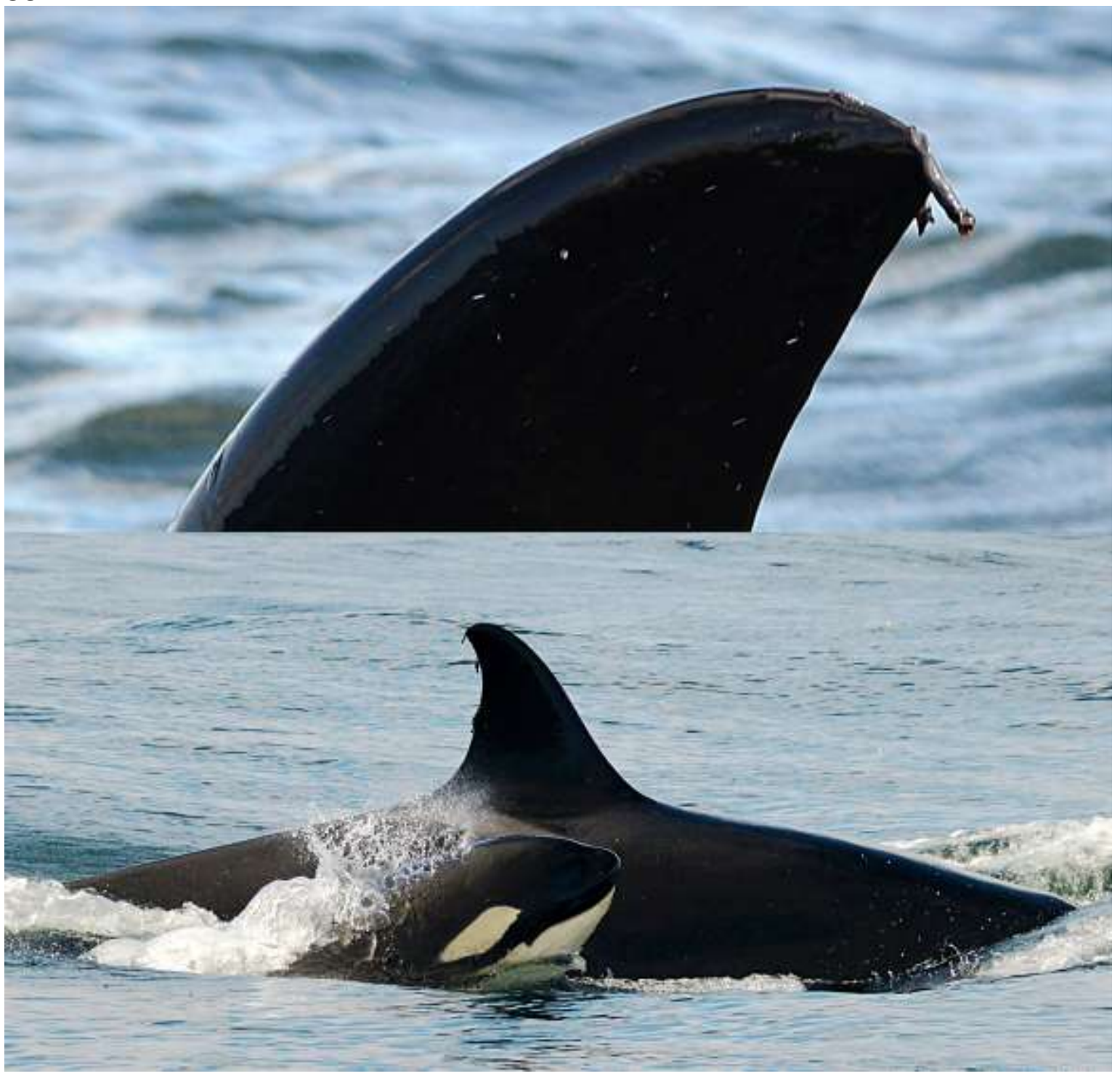

Fig. S1. Photographs of Xenobalanus globicipitis attached to the dorsal fin of a killer whale Orcinus orca in False Bay, South Africa (photo credits: D Hurwitz). 


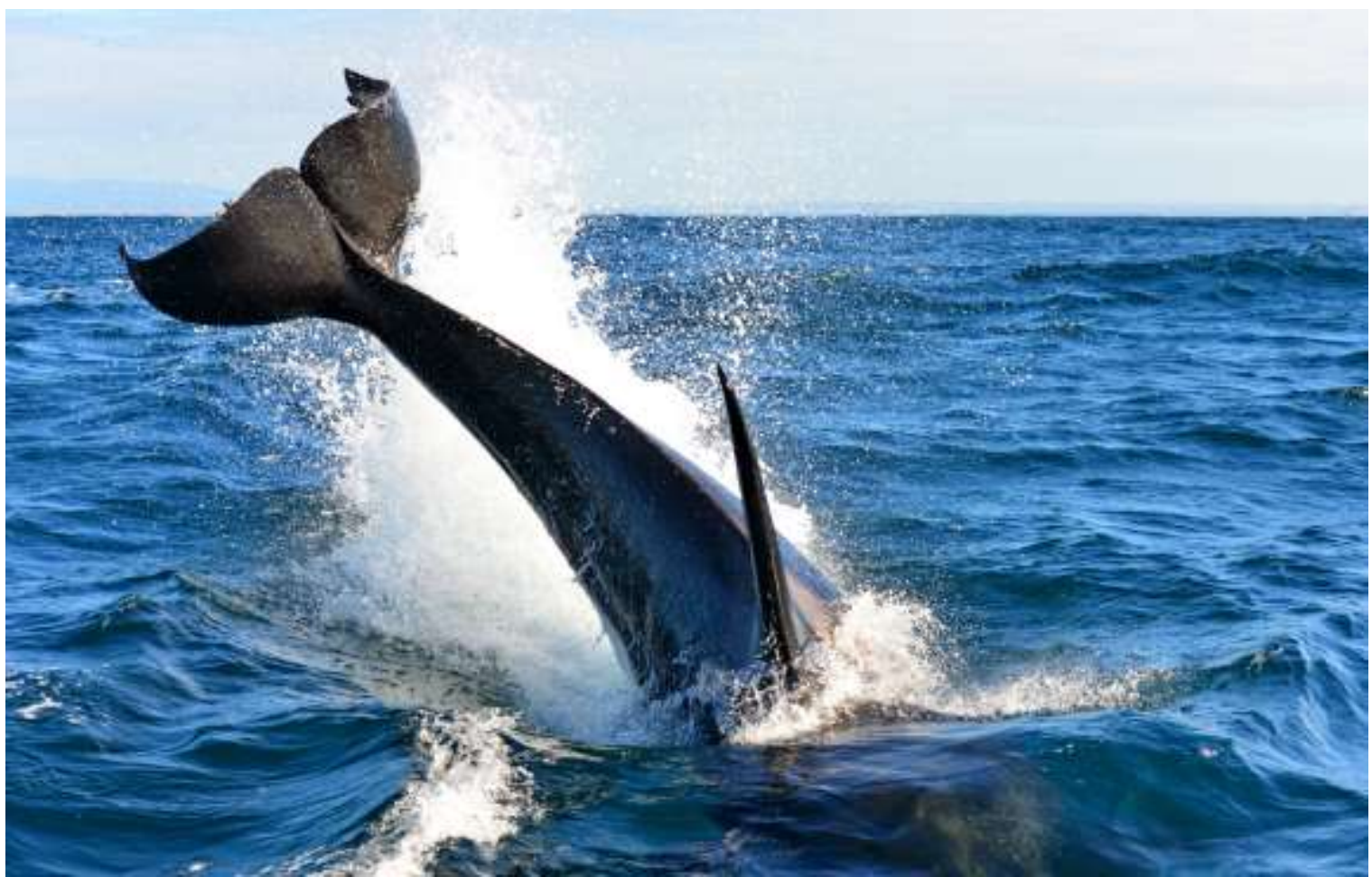

Fig. S2. Photograph of Xenobalanus globicipitis attached to the tail flukes of a killer whale Orcinus orca off the coast of Port Elizabeth, South Africa (photo credit: L Edwards). 